\title{
The effect of human gene therapy for $R P E 65$-associated Leber's congenital amaurosis on visual function: a systematic review and meta-analysis
}

\author{
Xue Wang ${ }^{1 \dagger}$, Chaofeng Yu ${ }^{2 \dagger}$, Radouil T. Tzekov ${ }^{3}$, Yihua Zhu ${ }^{4^{*}}$ and Wensheng Li $\mathrm{Li}^{1,2^{*}}$ (D)
}

\begin{abstract}
Background: RPE65-associated LCA (RPE65-LCA) is an inherited retinal degeneration caused by the mutations of RPE65 gene and gene therapy has been developed to be a promising treatment. This study aims to evaluate the association between changes in visual function and application of gene therapy in patients with RPE65-LCA.

Methods: Several databases (PubMed, Cochrane Library, and Web of Science) were searched for results of studies describing efficacy of gene therapy in patients with RPE65-LCA. Six studies, which included one randomized and five prospective non-randomized clinical trials, 164 eyes met our search criteria and were assessed.

Results: The BCVA significantly improved in treated eyes at 1 yr post treatment by $-0.10 \operatorname{logMAR}(95 \% \mathrm{Cl},-0.17$ $-0.04 ; p=0.002$ ), while there was no significant difference at $2-3$ years post treatment (WMD: $0.01 ; 95 \% \mathrm{Cl},-0.00$ $0.02 ; p=0.15)$. FST sensitivity to blue flashes also improved by $1.60 \log (95 \% \mathrm{Cl}, 0.66-2.55 ; p=0.0009)$, but no significant difference to red flashes (WMD: $0.86 ; 95 \% \mathrm{Cl},-0.29-2.01 ; p=0.14$ ) at $1 \mathrm{yr}$. There was no significant difference in central retinal thickness at $1 \mathrm{yr}$, but central retina in treated eyes appeared thinner at 2-3 years post treatment by $19.21 \mu \mathrm{m}(95 \% \mathrm{Cl},-34.22--4.20 ; p=0.01)$.

Conclusions: Human gene therapy is a pioneering treatment option for RPE65-LCA. Although its efficacy appears to be limited to less than 2 yrs after treatment, it carries the potential for further improvement and prolongation of efficacy.
\end{abstract}

Keywords: Gene therapy, Leber's congenital Amaurosis, Visual function, Meta-analysis

\section{Background}

Leber's Congenital Amaurosis (LCA) is a heterogeneous group of eye diseases with mostly autosomal recessive inheritance, characterized with nystagmus and severely decreased visual acuity in early infancy and complete blindness by the third-to-forth decade of life [1]. RPE65associated LCA (RPE65-LCA) is associated with mutations of the RPE65 gene encoding the retinoid isomerohydrolase in the retinal pigment epithelium (RPE), which result in rod-cone type retinal dystrophy [2] [3]. As a cutting-edge approach, human gene therapy was developed to compensate genetic deficiency and improve visual function of RPE65-LCA as early as 2008 [4-6]. Since then several studies reported that RPE65 gene therapy could improve visual function in RPE65-LCA; however, the overall level of efficacy remains somewhat uncertain and variable. Therefore, we systemically searched and analyzed the published literature in order to gain a better understanding of the effectiveness of human gene therapy on visual function in RPE65-LCA.

\footnotetext{
*Correspondence: zhuyihua889@163.com; drlws@qq.com

†Xue Wang, Chaofeng Yu contributed equally to this work.

${ }^{4}$ First Affiliated Hospital of Fujian Medical University, Fuzhou, China

${ }^{1}$ Aier School of Ophthalmology, Central South University, Changsha, China

Full list of author information is available at the end of the article
}

\section{Methods \\ This meta-analysis was confirmed to the recommenda- tions of the Cochrane Handbook and reported according to the PRISMA reporting guidelines for meta-analysis}


and systematic reviews [7]. The PRISMA checklist was provided in Additional file 1: Table S1.

\section{Search methods}

Online electronic databases (PubMed, Web of Science, and the Cochrane Library) were searched in November 2018 without restriction to region, date, language or publication types. The following $\mathrm{MeSH}$ terms and their combinations were used in [Title/Abstract]: Leber Congenital Amaurosis, RPE65 and gene therapy. Additionally, the web-based resource Clinical trials.gov (https:// clinicaltrials.gov) was used to complement the searches of the reference lists of all retrieved studies. When multiple published articles described the same population, the most recent or complete report was used.

\section{Inclusion and exclusion criteria}

All randomized controlled trials (RCTs) and observational studies that reported results of human gene therapy for RPE65-LCA, and that had at least one quantitative outcome of visual function mentioned, were included; however, review articles, meeting abstracts and pre-clinical studies were excluded.

\section{Study selection}

Figure 1 shows a flow chart of the selection process used to identify relevant studies. Data of included studies were extracted and summarized independently by two authors (X.W. and C.Y.). Any disagreement was resolved by the third expert (W.L.). The main outcomes were best-corrected visual acuity (BCVA), and the other outcomes were central retinal thickness, and Full-field Light Sensitivity Threshold (FST) Testing.

\section{Data collection and risk of bias assessment}

Studies were rated for the level of evidence provided according to criteria by the Centre for Evidence-Based Medicine (Oxford, UK). The methodological quality of all cohort studies was assessed by the Newcastle-Ottawa scale (NOS) [8], which consists of three factors: patient selection, comparability of the study groups, and assessment of outcome (Additional file 1: Table S2). A 10point scale was used and a score of 0-9 was allocated to each study except the RCT. The one randomized trial was considered to be of higher quality for the purposes of this analysis. Two reviewers (X.W. and C.Y.) assessed the quality of the studies. Any discrepancies were resolved by a third reviewer (W.L.). Randomized clinical

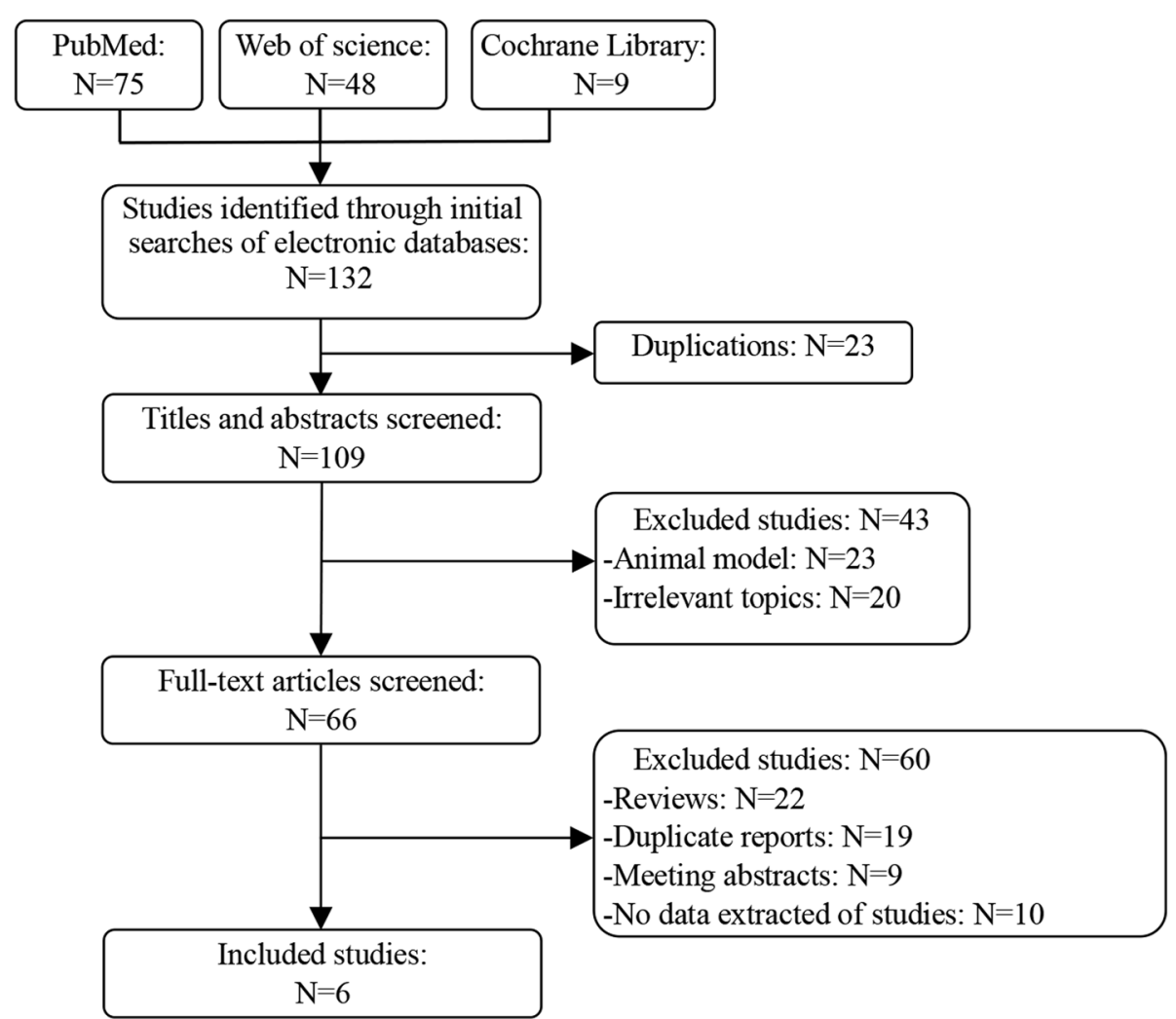

Fig. 1 Flow diagram of studies identified, included and excluded. 132 publications were identified from the literature research. Of these, 23 duplicates were removed, 23 were animal models, 20 were irrelevant topics, 22 were reviews, 19 were duplicate reports, 9 were meeting abstracts, and 10 were studies with not relevant data reported 
trials (RCTs) and cohort studies achieving a score of seven or more points were considered to be of high quality.

\section{Data synthesis and analysis}

All analyses were performed using Review Manager 5.3 (Cochrane Collaboration, Oxford, UK). The weighted mean difference (WMD) and risk ratio (RR) were used to analyze continuous and dichotomous variables, respectively. All results were reported with $95 \%$ confidence intervals (CIs). If continuous data were presented as means and range values, the standard deviation (SD) were calculated using the technique described by Hozo et al. [9]. Heterogeneity between studies was assessed by the $X^{2}$ and $\mathrm{I}^{2}$ statistic. The random-effects model was used if the $p$ value was less than $0 \cdot 1$, otherwise, the fixed-effects model was reported [10].

Subgroup analyses were performed to compare BCVA at baseline of less than or more than $1.3 \log$ MAR based on a recent study which reported that BCVA improvement was different between eyes with a baseline acuity at more than $1.3 \operatorname{logMAR}(\sim 20 / 400)$ vs. eyes with lower baseline BCVA [11]. Funnel plots were used to screen for potential publication bias.

\section{Results}

\section{Included studies}

Overall, 132 publications were identified using the predefined search algorithm (Fig. 1). Of these, 66 publications were related to our research topic. The breakdown of these publications was as follows: 22 were reviews, 19 were duplicate reports, 9 were meeting abstracts, and 10 were studies with not relevant data reported. Six studies with 164 eyes (82 patients) were included in the final analysis [12-17]. Agreement between the two reviewers was $100 \%$ for study selection and $83 \%$ for quality assessment of trials after examination of references listed for studies. Study outcomes were shown in Table 1.

\section{Characteristics of included studies}

The characteristics of included studies are shown in Table 2. Among the included studies, only one was a RCT [16], while five were prospective clinical trials $[12-15,17]$. These studies included eyes with wide range of baseline BCVA, ranging from light perception only to $0.31 \log$ MAR $(\sim 20 /$ 41). Of these, three studies had enough data to allow stratification by baseline BCVA and a subgroup analysis was carried based on the baseline BCVA [13, 15, 17]. The remaining three studies had insufficient data for this type of sub-analysis. In terms of follow-up period of observation, the effectiveness of more than one result related to visual function assessment were recorded at only the 1-year posttreatment interval for one study [16]; while two studies had recorded the effectiveness only at $2-3$ years $[12,15]$. The remaining three studies had results available at both 1 year and $2-3$ years post-treatment $[13,14,17]$.

\section{Methodological quality of included studies}

The quality of included studies was relatively high, with an average score of 7.3. True randomization was used in only one RCT [16]. For the RCT where treatment was administered bilaterally, visual function parameters were averaged for both eyes and recorded as one value used in the statistical analysis, while in the five prospective studies treatment was administered unilaterally and visual function was assessed and reported bilaterally. None of the prospective studies provided information about allocation sequence generation and concealment or about the blinding method. Matching criteria between two groups were variable. Apart from the RCT, the eye of each participant with the poorer visual acuity was selected as the study eye, and the contralateral eye served as an untreated control, therefore, the BCVA at baseline was not matched.

\section{Main outcomes \\ Mean change in BCVA}

BCVA was measured using the Early Treatment Diabetic Retinopathy Study (ETDRS) method, and the acuity was

Table 1 Results of meta-analysis comparison of treated and untreated group

\begin{tabular}{|c|c|c|c|c|c|c|c|c|c|}
\hline \multirow[t]{2}{*}{ Outcomes of interest } & \multirow{2}{*}{$\begin{array}{l}\text { Studies, } \\
\text { no. }\end{array}$} & \multirow{2}{*}{$\begin{array}{l}\text { Treated } \\
\text { Eyes, } \\
\text { no. }\end{array}$} & \multirow{2}{*}{$\begin{array}{l}\text { Untreated } \\
\text { Eyes, no. }\end{array}$} & \multirow[t]{2}{*}{ WMD/RR (95\%CL) } & \multirow{2}{*}{$\begin{array}{l}P \\
\text { value }\end{array}$} & \multicolumn{4}{|c|}{ Study heterogeneity } \\
\hline & & & & & & $\bar{x}^{2}$ & $\mathrm{df}$ & $1^{2}, \%$ & P value \\
\hline \multicolumn{10}{|l|}{ Main outcomes } \\
\hline Mean BCVA change at 1 year & 4 & 57 & 41 & $-0.10(-0.17$ to -0.04$)$ & 0.002 & 8.88 & 5 & 44 & 0.11 \\
\hline Mean BCVA change at $2-3$ years & 4 & 31 & 32 & $0.01(-0.00$ to 0.02$)$ & 0.15 & 6.80 & 5 & 27 & 0.24 \\
\hline \multicolumn{10}{|l|}{ Other outcomes } \\
\hline FST sensitivity to red flashes & 2 & 37 & 21 & $0.86(-0.29$ to 2.01$)$ & 0.14 & 18.32 & 1 & 95 & $<0.0001$ \\
\hline FST sensitivity to blue flashes & 2 & 37 & 21 & $1.60(0.66$ to 2.55$)$ & 0.0009 & 3.25 & 1 & 69 & 0.07 \\
\hline Change in central retinal thickness at 1 year & 2 & 52 & 30 & $-11.68(-32.49$ to 9.14$)$ & 0.27 & 4.21 & 1 & 76 & 0.04 \\
\hline Change in central retinal thickness at $2-3$ years & 2 & 18 & 18 & $-19.21(-34.22$ to -4.20$)$ & 0.01 & 0.38 & 1 & 0 & 0.54 \\
\hline
\end{tabular}


Table 2 Characteristics of included studies

\begin{tabular}{|c|c|c|c|c|c|c|c|c|c|}
\hline \multirow[t]{2}{*}{ Studies } & \multirow{2}{*}{$\begin{array}{l}\mathrm{Age}^{\&} \\
\text { (years) }\end{array}$} & \multirow{2}{*}{$\begin{array}{l}\text { Type of } \\
\text { study }\end{array}$} & \multicolumn{2}{|c|}{ Number of eyes enrolled } & \multicolumn{2}{|c|}{ Eye stratified by BCVA } & \multirow{2}{*}{$\begin{array}{l}\text { Follow-up } \\
\text { (months) }\end{array}$} & \multirow{2}{*}{$\begin{array}{l}\text { Outcome } \\
\text { measures used }\end{array}$} & \multirow{2}{*}{$\begin{array}{l}\text { Quality } \\
\text { score }\end{array}$} \\
\hline & & & Treated & Untreated & Better BCVA* & Worse $\mathrm{BCVA}^{*}$ & & & \\
\hline Jacobscon.et al. 2012 [12] & 20 & $\bar{P}$ & 15 & 15 & $11 / 11$ & $4 / 4$ & 36 & CRT, FST & 7.5 \\
\hline Testa.et al. 2013 [13] & 20 & P & 5 & 5 & $2 / 3$ & $3 / 2$ & $12-36$ & BCVA & 6.5 \\
\hline Bainbridge.et al. 2015 [14] & 14 & P & 12 & 12 & $11 / 11$ & $1 / 1$ & $12-36$ & BCVA, CRT & 7.5 \\
\hline Weleber.et al. 2016 [15] & 25 & $P$ & 12 & 12 & $7 / 7$ & $5 / 5$ & 24 & BCVA & 7.5 \\
\hline Russell.et al. 2017 [16] & 15 & RCT & $40^{\#}$ & $18^{\#}$ & $32^{\#} / 16^{\#}$ & $8^{\#} / 2^{\#}$ & 12 & BCVA, CRT, FST & RCT \\
\hline Le Meur.et al. 2018 [17] & 24 & $P$ & 9 & 9 & $5 / 7$ & $4 / 2$ & $12-36$ & BCVA & 7.5 \\
\hline
\end{tabular}

\& - average age at recruitment (years)

\# - bilateral administration

*Better BCVA - baseline BCVA better than 1.3 logMAR; *Worse BCVA - baseline BCVA worse than 1.3 logMAR

Legend: P - prospective clinical trial; RCT - randomized controlled clinical trial; BCVA - best-corrected visual acuity; CRT - central retinal thickness; FST - full-field sensitivity threshold

scored as the number of letters read after adjusting for distance and expressed as logMAR. Pooling the data from four studies $[13,14,16,17]$ that assessed BCVA in 98 eyes from 49 patients showed that BCVA improved significantly in treated eyes compared to untreated eyes at $1 \mathrm{yr}$ post treatment by $-0.1 \log$ MAR (95\% CI, -0.17 to $-0.04 ; p=0.002)$, with no significant heterogeneity between studies $\left(X^{2}=8.88\right.$, $\mathrm{df}=5, p=0.11 ; \mathrm{I}^{2}=44 \%$ ) (Fig. 2a).

At later follow-up time points $(2-3$ years post treatment), four studies [13-15, 17] including 63 eyes from 32 patients had data allowing estimation of BCVA change. The pooled data showed no significant difference between treated vs. untreated eyes (WMD: 0.01; 95\% CI, -0.00 to $0.02 ; p=0.15$ ), with no significant heterogeneity between studies $\left(\mathrm{X}^{2}=6.80, \mathrm{df}=5, p=0.24 ; \mathrm{I}^{2}=27 \%\right)$ (Fig. $2 \mathrm{~b}$ ).

\section{Subgroup analysis}

When treated eyes were compared with untreated eyes in patients with baseline acuity better than $1.3 \log$ MAR, it appeared that BCVA in treated eyes improved significantly by $-0.11 \operatorname{logMAR}$ (or more than one line on the ETRDS chart) at one-year post-treatment $(95 \% \mathrm{CI}$, $0.18--0.04 ; p=0.002)$. However, there was no significant difference in BCVA change at 2-3 years of followup (WMD: -0.06; 95\% CI, $-0.15-0.03 ; p=0.22$ ).

Furthermore, when BCVA in eyes with a baseline acuity of more than $1.3 \operatorname{logMAR}$ were compared, there was no significant difference between mean BCVA change at the $1 \mathrm{yr}$ post treatment visit (WMD: -0.00 ; 95\% CI, $0.25-0.24 ; p=0.98$ ), and also at $2-3$ years post treatment (WMD: 0.01; 95\% CI, $-0.00-0.02 ; p=0.11$ ).

\section{Other outcomes}

\section{Change in FST sensitivity}

FST was performed using a LED-based Ganzfeld stimulator, red and blue stimuli were used to probe differential effects on cone versus rod photoreceptors [18]. FST sensitivity to red flashes data were available for 58 eyes $(29$ patients) across two studies $[12,16]$. The mean change was higher by $\sim 0.86 \log$ in the treated eyes vs. untreated eyes, but the difference was not statistically significant $(95 \% \mathrm{CI}$, - 0.29-2.01; $p=0.14)$, with significant between-study heterogeneity $\left(\chi^{2}=18.32, \mathrm{df}=1, p<0.0001 ; \mathrm{I}^{2}=95 \%\right)$ (Fig. 3a).

Additionally, FST sensitivity to blue flashes data were also available for 58 eyes (29 patients) across two studies [12, 16]. The mean change was significantly higher in the treated eyes vs. untreated eyes by $\sim 1.60 \log (95 \% \mathrm{CI}, 0.66-$ $2.55 ; p=0.0009)$, with no significant between-study heterogeneity $\left(x^{2}=3.25, d f=1, p=0.07 ; I^{2}=69 \%\right)$ (Fig. $\left.3 b\right)$.

\section{Change in central retinal thickness}

Total thickness of central retinal was measured using spectral domain optical coherence tomography. Two studies $[14,16]$ that assessed 82 eyes from 41 patients reported on change in central retinal thickness at the 1 yr visit. Despite some tendency for more pronounced thinning in the central retina of treated eyes, the analysis showed no significant difference between the treated vs. untreated eyes (WMD: -11.68 ; 95\% CI, $-32.49-9.14 ; p=0.27$ ), with significant between-study heterogeneity $\left(\chi^{2}=4.21, \mathrm{df}=1\right.$, $\mathrm{p}=0.04 ; \mathrm{I}^{2}=76 \%$ ) (Fig. 4a).

At later follow-ups (2-3 years after treatment), two studies [12, 14] including 36 eyes from 18 patients assessed central retinal thickness, which showed that the change in central retinal thickness was on average $\sim 19.21 \mu \mathrm{m}$ lower in treated eyes compared to untreated eyes (95\% CI, $34.22--4.20 ; p=0.01)$, with no significant between-study heterogeneity $\left(\mathrm{X}^{2}=0.38, \mathrm{df}=1, p=0.54 ; \mathrm{I}^{2}=0 \%\right)(\mathrm{Fig}$. 4b).

\section{Publication bias}

Figure 5 shows a funnel plot of the studies included in this meta-analysis that reported mean change in BCVA at year one visit. All studies lie inside the $95 \%$ CIs, with an even distribution around the vertical, indicating no obvious publication bias. 


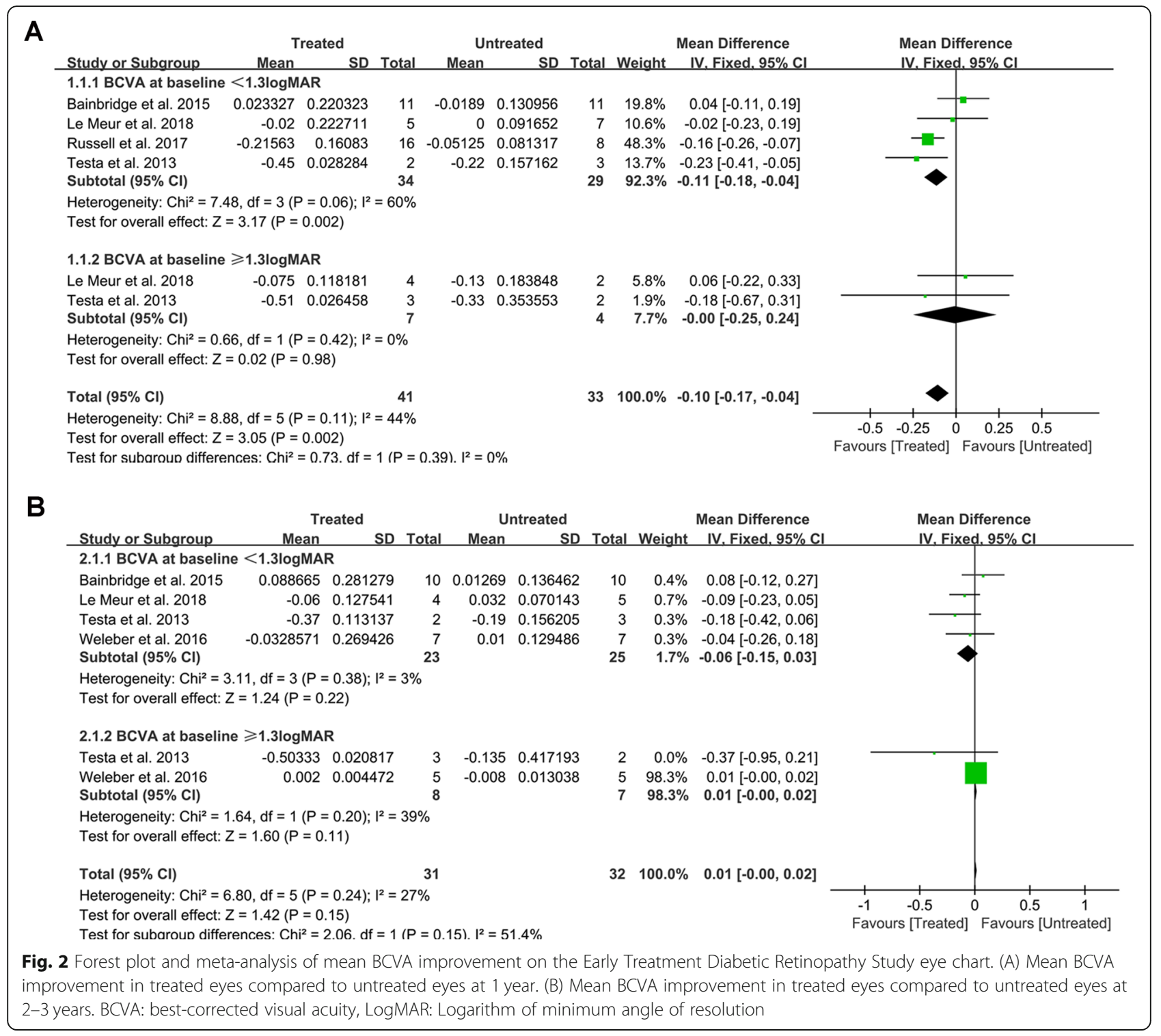

\section{Discussion}

This meta-analysis summarizes the results from one randomized and five prospective clinical trials, including 164 eyes from 82 patients and comparing visual function of treated vs. untreated eyes. It showed that, in terms of improvement of best-corrected visual acuity and fullfield light sensitivity threshold to blue flashes, gene therapy was effective up to 2 yrs post treatment. However, the improvement in BCVA was not sustainable and the data were not available in FST sensitivity beyond 2 yrs post treatment.

Recent studies indicate a good safety profile for this type of treatment, with no difference at the rate of serious ocular adverse events even at 5 yrs post treatment [11]. However, there are some indications that the retinal degeneration associated with the disease may be occurring faster in treated eyes compared to non-treated eyes. Thus, some tendency for thinning was apparent even at $1 \mathrm{yr}$ post treatment, although the difference was not statistically significant. More importantly, at later follow-up time points (2-3 years post treatment), the analysis showed significant thinning of the central retina in treated eyes vs. non-treated eyes. The average difference in thinning of $\sim 19 \mu \mathrm{m}$ at $2-3$ years between the two groups appears to be also clinically significant as it translates to $\sim 8 \%$ difference in thickness, assuming $250 \mu \mathrm{m}$ average central retinal thickness. Although the reason for this deference in central retinal thickness at more than 2 years post treatment is currently unknown, it can be hypothesized that temporary retinal edema or detachment caused by the subretinal injection had some limited, but measurable and lasting damage to the retinal structure which ended up thinner upon resolving the edema or detachment. Besides, the eyes selected for 


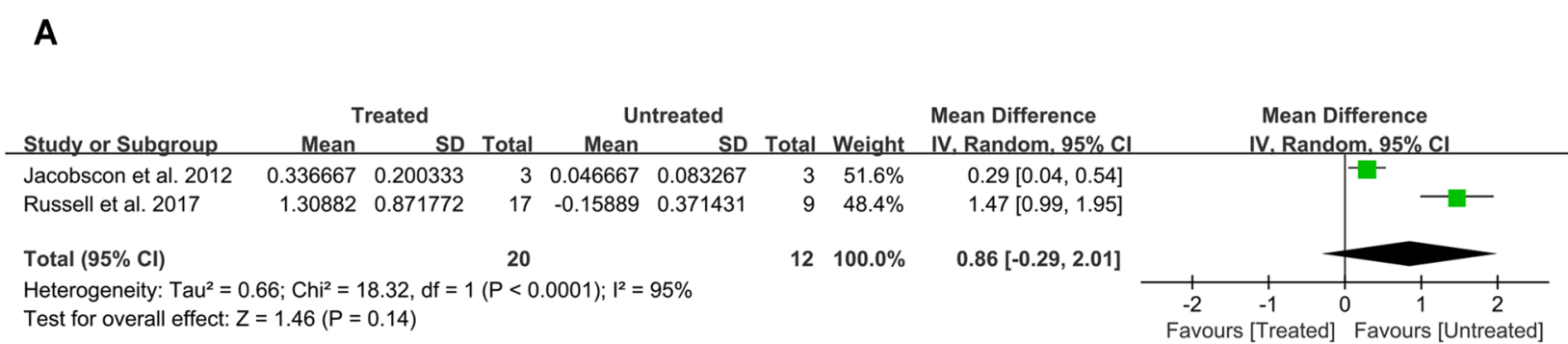

B

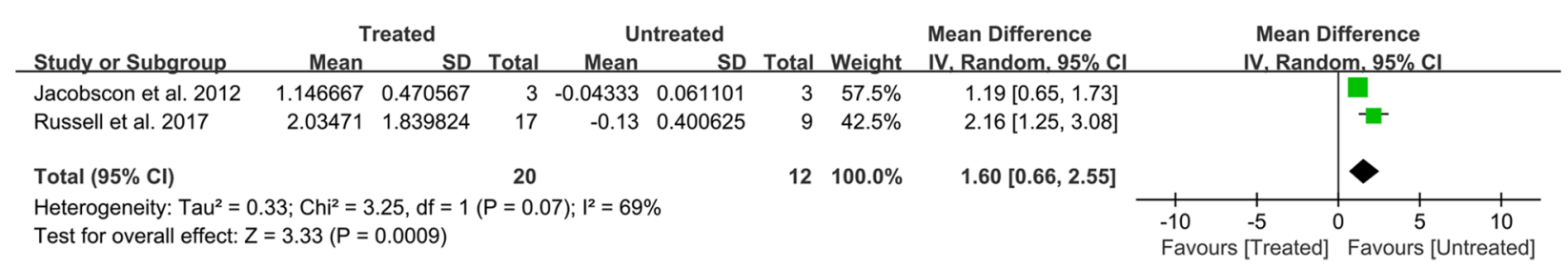

Fig. 3 Forest plot and meta-analysis of FST sensitivity improvement. (A) FST sensitivity improvement to red flashes in the treated eyes vs. untreated eyes. (B) FST sensitivity improvement to blue flashes in the treated eyes vs. untreated eyes. FST: Full-field Light Sensitivity Threshold

treatment with gene therapy had relatively worse baseline visual acuity vs. untreated eyes, with an average difference of $0.33 \log$ MAR (or more than 3 lines on the ETDRS chart), which might indicate a more advanced stage of the disease.

The effects of any human gene therapy are complex and multifaceted. The results from this meta-analysis indicate that gene therapy does not slow visual function loss in the long term (beyond 2 yrs). Visual function loss in LCA is caused by a combination of biochemical chromophore deficiency and progressive degeneration of photoreceptor cells [19], but gene therapy appears to address only the biochemical chromophore deficiency under the premise of a certain proportion of surviving photoreceptor cells. However, continuing loss of visual function from the ongoing retinal degeneration can still occur following initial improvement from gene therapy. Thus, in order to improve future efficacy, it may be beneficial to administer combinatorial agents supplementing the gene therapy with the goal to prevent further loss of retinal cells. A study by Cideciyan et al. demonstrates advancing retinal degeneration despite visual improvement after gene therapy for RPE65-LCA, and suggests the need for a combinatorial strategy to improve vision function in short term but also to slow retinal degeneration in the long term [20]. Potential agents to be

\section{A}

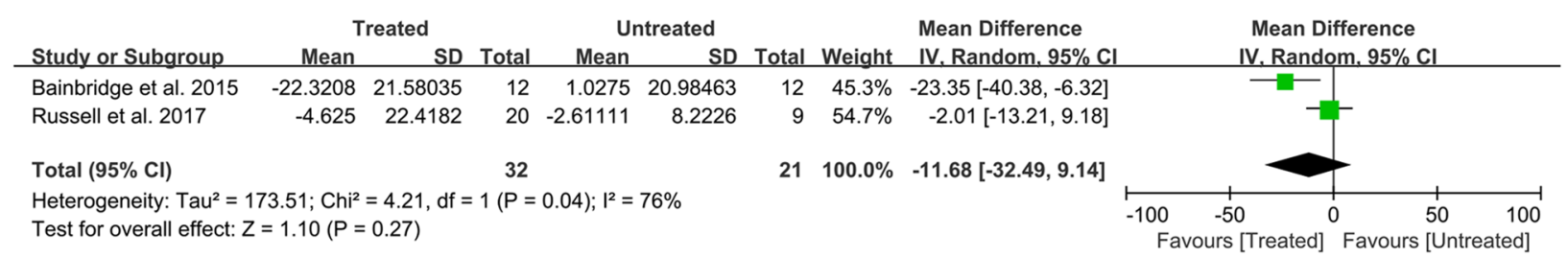

B

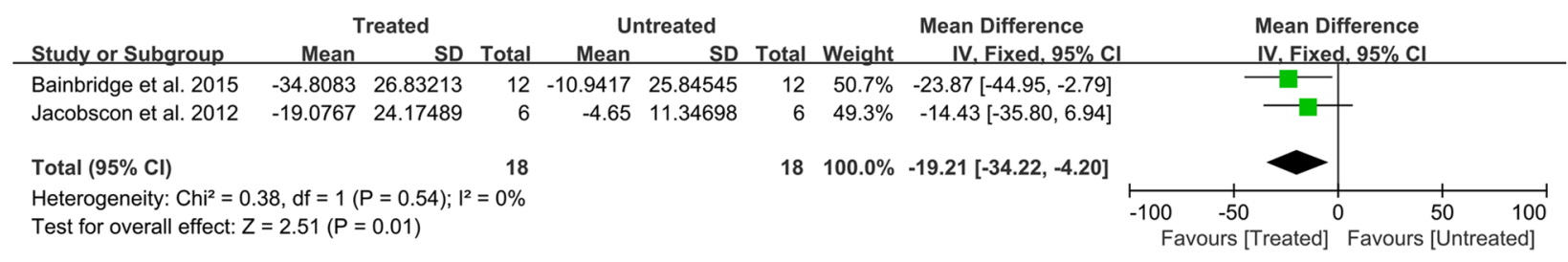

Fig. 4 Forest plot and meta-analysis of retinal degeneration at 1 year (a) and 2-3 years (b) post-treatment 


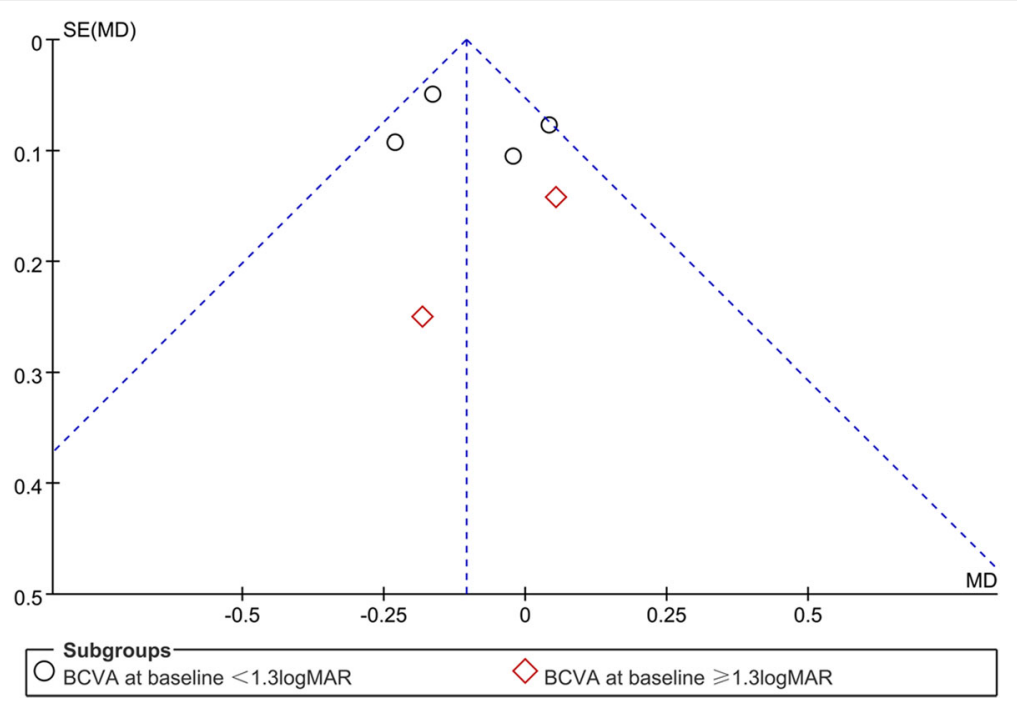

Fig. 5 Funnel plots illustrating meta-analysis of mean BCVA improvement at 1 year. $\mathrm{SE}=$ standard error; $\mathrm{MD}=$ mean deviation

considered as part of the combinatorial therapy could be neuroprotective, prosurvival, antiapoptotic factors or antioxidants. These agents could be a significant factor delaying or preventing continuing cone photoreceptor cell loss observed in animal models of inherited retinal degenerative diseases [21-23], administered either simultaneously or sequentially with gene therapy. One example of such agent could be l-cysteine, as it was recently shown to be neuroprotective for RPE $[24,25]$. One downside of the implementation of this approach is that regulatory agencies (e.g. FDA in the US, EMA in Europe, etc.) may require separate studies to evaluate safety and efficacy on each one of these components, unless there is sufficient animal data to support additive effects.

In the advanced or endstage of the disease, it is likely that the structure of the outer retina has already undergone considerable damage, and gene therapy might not be able to regenerate most photoreceptor cells, likely damaged beyond repair. Therefore, emerging techniques, such as stem cell transplantation and retinal prosthesis, may be proposed as therapeutic strategies to restore visual function. When analyzing the BCVA data it became apparent that, surprisingly, some contralateral (untreated) eyes showed improvement in BCVA after treatment [1215]. This phenomenon makes it complicated to estimate the "true" improvement of BCVA as the treatment effect was based on a comparison between treated vs. contralateral (untreated) eyes. Although a small learning effect may contribute to this phenomenon, it is likely that the main cause of this effect is related other factors. One such factor could be a reorganization of the receptive fields of retinal ganglion cells which could be due to efferent influences or even direct retino-retinal connections [26, 27]. Further studies including visual electrophysiological tests would be helpful to understand the origin of this improvement.

In the studies subject to this meta-analysis, visual function was tested in several different ways. One of the methods used was testing FST in dark-adapted eyes by stimulating the retina with red or blue flashes. It is generally accepted that red FST flashes stimulate more effectively the cone population (mainly L-cones), while blue flashes stimulate preferentially the rods (and some S-cones). The FST sensitivity analysis showed that gene therapy improved the rod function by $\sim 137 \%$ and cone function by $\sim 89 \%$ vs. baseline in the treated eyes at $1 \mathrm{yr}$ post treatment, but there was no significant difference between treated vs. untreated eyes at that time point in sensitivity to red flashes (reflecting dark-adapted cone function). This finding suggests that human RPE65 gene therapy has a stronger positive effect on rod photoreceptor function. Besides, there may be an additional factor influencing the observed discrepancy between rod and cone function improvement. Both types of stimulation stimulated the total retinal area, however, the subretinal injection was generally limited to the macula, which has a relatively small size compared to the total retinal area $(<3 \%)$. Although the cone density is lower in the periphery, the overall number of cones in the periphery is much higher compared to the number of cones in the macula (> 10 times) [28]. Therefore, even if the function of the central cones has improved (as suggested by the improvement in BCVA), this positive change may be too small to be reflected in the global response from all cones. A better parameter to detect visual function improvement after gene therapy would be visual field testing (kinetic perimetry, static automated perimetry, microperimetry, etc.). However, the visual field outcome measures used in the studies 
analyzed here were too varied and prevented us from conducting a rigorous meta-analysis. Nevertheless, from Russel et al. and Weleber et al., it was implied that the fovea could be particularly vulnerable to degeneration in LCA $[15,16]$. Russel et al. concluded that Humphrey macula sensitivity threshold was increased in the intervention group, but Humphrey foveal sensitivity threshold was not. And Weleber et al. concluded that $V_{30}$ increased in 6 patients, while $\mathrm{V}_{\text {TOT }}$ increased in 5 patients vs. kinetic visual field area improved in only 3 patients in the treated eye. It is possible that foveal and extrafoveal cones do not have the same relationship with RPE apical processes and contributions of the chromophore required from retinal and RPE visual cycle pathways may also differ between foveal and extrafoveal cones [29, 30].

Between-study heterogeneity was not significant for most of the outcomes except for FST sensitivity to red flashes and the change in central retinal thickness at $1 \mathrm{yr}$. The difference in sample size, follow-up time points, and bilateral or unilateral administration among the studies might have contributed to the significant between-study heterogeneity for these parameters. The random-effects model was used to reduce the effect of heterogeneity but did not eliminate it completely.

This meta-analysis has some limitations that need to be taken into account. The main limitation is the insufficient number of RCTs (only one available) resulting in inadequate random sequence generation and blinding leading to an increased risk of bias. However, it has to be noted that RPE65-LCA is a rare disease with an estimated prevalence of about 1:80,000, and the incidence of RPE65-LCA would be about $6 \%$ of all LCA [31,32]. Finding patients for such a rare disease is a challenge and is difficult to anticipate an adequate number of RCT trials to appear in the near future. Besides, there was a lack of available data for subgroup analysis based on stratification of the endpoints in the current analysis (except BCVA). However, according to the subgroup analysis of BCVA, the effectiveness of gene therapy with different baseline acuity might be inconsistent. Finally, as enough data at comparable follow-up time points was lacking, the analysis could not accurately assess timedependent effectiveness beyond the relatively crude separation of $1 \mathrm{yr}$ vs. 2-3 yrs of follow-up.

Although all the limitations listed in the previous paragraph, the results appeared relatively homogenous (except FST to red flash and central retinal thickness change at $1 \mathrm{yr}$ visit) and seemed to suggest that results of the meta-analysis were still valid. The recent availability of data related to the visual outcomes of clinical trials using gene therapy for of RPE65-LCA proved fortunate as enough data are now available for an initial evaluation by meta-analytical methods. However, this should be considered only an initial evaluation of this type of therapy, which would become without doubt an important and expanding field of future clinical research.

\section{Conclusions}

In summary, this meta-analysis indicates that RPE65 gene therapy is associated with an improvement of BCVA and FST sensitivity to blue flashes in the short-term (up to 2 yrs post treatment). Visual function appears to be equivalent in the longer term ( 2 yrs and beyond) in terms of change in the visual function measures analyzed here like BCVA. The inherent limitations of included studies may have an impact on precise conclusion several important aspects of efficacy. Only larger-scale, well-designed RCTs would be able to clarify these aspects and provide further insight and guidance into the benefits and risks associated with RPE65-LCA gene therapy.

\section{Supplementary information}

Supplementary information accompanies this paper at https://doi.org/10. 1186/s13023-020-1304-1.

Additional file 1: Table S1. PRISMA checklist. Table S2. Risk of bias in cohort studies using Newcastle Ottawa scale (NOS).

\section{Abbreviations}

BCVA: Best-corrected visual acuity; Cl: Confidence interval; CRT: Central retinal thickness; ETDRS: Early Treatment Diabetic Retinopathy Study; FST: Full-field Light Sensitivity Threshold; LCA: Leber's Congenital Amaurosis; MD: Mean deviation; NOS: Newcastle-Ottawa scale; RCT: Randomized controlled trial; RPE: Retinal pigment epithelium; RR: Risk ratio; SD: Standard deviation; SE: Standard error; WMD: Weighted mean difference

\section{Acknowledgements}

No applicable.

\section{Authors' contributions}

X.W. and C.Y. contributed to the conception of the work. X.W. and C.Y. searched the literature and extracted the data. X.W. and R.T. wrote the manuscript. W.L. and Y.Z. revised the manuscript and produced the final version. All authors read and approved the final manuscript.

\section{Funding}

This work was supported by National Natural Science Foundation of China (No.81570875).

Availability of data and materials

Data are available from the authors upon request.

Ethics approval and consent to participate

Not applicable.

Consent for publication

No applicable.

\section{Competing interests}

The authors declare that they have no competing interests..

\section{Author details}

${ }^{1}$ Aier School of Ophthalmology, Central South University, Changsha, China. ${ }^{2}$ Shanghai Aier Eye Hospital, 1286 Hongqiao Road, Shanghai, China.

${ }^{3}$ Department of Ophthalmology, University of South Florida, Tampa, Florida, USA. ${ }^{4}$ First Affiliated Hospital of Fujian Medical University, Fuzhou, China. 
Received: 20 October 2019 Accepted: 13 January 2020

Published online: 14 February 2020

\section{References}

1. Allikmets R. Leber congenital amaurosis: a genetic paradigm. Ophthalmic Genet. 2004;25(2):67-79.

2. Lorenz B, Gyurus P, Preising M, Bremser D, Gu S, Andrassi M, Gerth C, Gal A. Early-onset severe rod-cone dystrophy in young children with RPE65 mutations. Invest Ophthalmol Vis Sci. 2000;41(9):2735-42.

3. Redmond TM, Poliakov E, Yu S, Tsai JY, Lu Z, Gentleman S. Mutation of key residues of RPE65 abolishes its enzymatic role as isomerohydrolase in the visual cycle. Proc Natl Acad Sci U S A. 2005;102(38):13658-63.

4. Bainbridge JW, Smith AJ, Barker SS, Robbie S, Henderson R, Balaggan K, Viswanathan A, Holder GE, Stockman A, Tyler N, et al. Effect of gene therapy on visual function in Leber's congenital amaurosis. N Engl J Med. 2008; 358(21):2231-9.

5. Hauswirth WW, Aleman TS, Kaushal S, Cideciyan AV, Schwartz SB, Wang L, Conlon TJ, Boye SL, Flotte TR, Byrne BJ, et al. Treatment of leber congenital amaurosis due to RPE65 mutations by ocular subretinal injection of adenoassociated virus gene vector: short-term results of a phase I trial. Hum Gene Ther. 2008;19(10):979-90

6. Maguire AM, Simonelli F, Pierce EA, Pugh EN Jr, Mingozzi F, Bennicelli J, Banfi S, Marshall KA, Testa F, Surace EM, et al. Safety and efficacy of gene transfer for Leber's congenital amaurosis. N Engl J Med. 2008; 358(21):2240-8.

7. Knobloch K, Yoon U, Vogt PM. Preferred reporting items for systematic reviews and meta-analyses (PRISMA) statement and publication bias. J Craniomaxillofac Surg. 2011;39(2):91-2.

8. Wells G, Shea B, O'Connell D, Peterson J, Welch V, Losos M, Tugwell P, The Newcastle-Ottawa Scale (NOS) for assessing the quality of nonrandomised studies in meta-analyses [http://www.ohri.ca/programs/clinical_ epidemiology/oxford.asp].

9. Hozo SP, Djulbegovic B, Hozo I. Estimating the mean and variance from the median, range, and the size of a sample. BMC Med Res Methodol. 2005;5:13.

10. Lau J, loannidis JP, Schmid CH. Quantitative synthesis in systematic reviews. Ann Intern Med. 1997;127(9):820-6.

11. Pennesi ME, Weleber RG, Yang P, Whitebirch C, Thean B, Flotte TR, Humphries M, Chegarnov E, Beasley KN, Stout JT, et al. Results at 5 years after gene therapy for RPE65-deficient retinal dystrophy. Hum Gene Ther. 2018.

12. Jacobson SG, Cideciyan AV, Ratnakaram R, Heon E, Schwartz SB, Roman AJ, Peden MC, Aleman TS, Boye SL, Sumaroka A, et al. Gene therapy for leber congenital amaurosis caused by RPE65 mutations: safety and efficacy in 15 children and adults followed up to 3 years. Arch Ophthalmol. 2012;130(1):9-24.

13. Testa F, Maguire AM, Rossi S, Pierce EA, Melillo P, Marshall K, Banfi S, Surace EM, Sun J, Acerra C, et al. Three-year follow-up after unilateral subretinal delivery of adeno-associated virus in patients with Leber congenital Amaurosis type 2. Ophthalmology. 2013;120(6):1283-91.

14. Bainbridge JW, Mehat MS, Sundaram V, Robbie SJ, Barker SE, Ripamonti C, Georgiadis A, Mowat FM, Beattie SG, Gardner PJ, et al. Long-term effect of gene therapy on Leber's congenital amaurosis. N Engl J Med. 2015;372(20):1887-97.

15. Weleber RG, Pennesi ME, Wilson DJ, Kaushal S, Erker LR, Jensen L, McBride MT, Flotte TR, Humphries M, Calcedo R, et al. Results at 2 years after gene therapy for RPE65-deficient Leber congenital Amaurosis and severe earlychildhood-onset retinal dystrophy. Ophthalmology. 2016;123(7):1606-20.

16. Russell S, Bennett J, Wellman JA, Chung DC, Yu ZF, Tillman A, Wittes J, Pappas J, Elci O, McCague $S$, et al. Efficacy and safety of voretigene neparvovec (AAV2-hRPE65V2) in patients with RPE65-mediated inherited retinal dystrophy: a randomised, controlled, open-label, phase 3 trial. Lancet. 2017;390(10097):849-60.

17. Le Meur G, Lebranchu P, Billaud F, Adjali O, Schmitt S, Bezieau S, Pereon Y, Valabregue R, Ivan C, Darmon C, et al. Safety and long-term efficacy of AAV4 gene therapy in patients with RPE65 Leber congenital Amaurosis. Mol Ther. 2018;26(1):256-68.

18. Roman AJ, Cideciyan AV, Aleman TS, Jacobson SG. Full-field stimulus testing (FST) to quantify visual perception in severely blind candidates for treatment trials. Physiol Meas. 2007;28(8):N51-6.

19. Cideciyan AV. Leber congenital amaurosis due to RPE65 mutations and its treatment with gene therapy. Prog Retin Eye Res. 2010;29(5):398-427.

20. Cideciyan AV, Jacobson SG, Beltran WA, Sumaroka A, Swider M, Iwabe S, Roman AJ, Olivares MB, Schwartz SB, Komaromy AM, et al. Human retinal gene therapy for Leber congenital amaurosis shows advancing retinal degeneration despite enduring visual improvement. Proc Natl Acad Sci U S A. 2013;110(6):E517-25.

21. Dalkara D, Kolstad KD, Guerin Kl, Hoffmann NV, Visel M, Klimczak RR, Schaffer DV, Flannery JG. AAV mediated GDNF secretion from retinal glia slows down retinal degeneration in a rat model of retinitis pigmentosa. Mol Ther. 2011;19(9):1602-8.

22. Ohnaka M, Miki K, Gong YY, Stevens R, Iwase T, Hackett SF, Campochiaro PA. Long-term expression of glial cell line-derived neurotrophic factor slows, but does not stop retinal degeneration in a model of retinitis pigmentosa. J Neurochem. 2012;122(5):1047-53.

23. Trifunovic D, Sahaboglu A, Kaur J, Mencl S, Zrenner E, Ueffing M, ArangoGonzalez B, Paquet-Durand F. Neuroprotective strategies for the treatment of inherited photoreceptor degeneration. Curr Mol Med. 2012;12(5):598-612

24. Carver KA, Yang D. N-Acetylcysteine amide protects against oxidative stressinduced microparticle release from human retinal pigment epithelial cells. Invest Ophthalmol Vis Sci. 2016;57(2):360-71.

25. Terluk MR, Ebeling MC, Fisher CR, Kapphahn RJ, Yuan C, Kartha RV, Montezuma SR, Ferrington DA. N-acetyl-L-cysteine protects human retinal pigment epithelial cells from oxidative damage: implications for age-related macular degeneration. Oxidative Med Cell Longev. 2019;2019:5174957.

26. Ortiz G, Odom NV, Passaglia CL, Tzekov RT. Efferent influences on the bioelectrical activity of the retina in primates. Doc Ophthalmol. 2016;134(1):57-73.

27. Tang X, Tzekov R, Passaglia CL. Retinal cross talk in the mammalian visual system. J Neurophysiol. 2016;115(6):3018-29.

28. Curcio CA, Sloan KR, Kalina RE, Hendrickson AE. Human photoreceptor topography. J Comp Neurol. 1990;292(4):497-523.

29. Anderson DH, Fisher SK. The relationship of primate foveal cones to the pigment epithelium. J Ultrastruct Res. 1979;67(1):23-32

30. Wang JS, Kefalov VJ. The cone-specific visual cycle. Prog Retin Eye Res. 2011; 30(2):115-28.

31. den Hollander Al, Roepman R, Koenekoop RK, Cremers FP. Leber congenital amaurosis: genes, proteins and disease mechanisms. Prog Retin Eye Res. 2008;27(4):391-419.

32. Stone EM. Leber congenital amaurosis - a model for efficient genetic testing of heterogeneous disorders: LXIV Edward Jackson memorial lecture. Am J Ophthalmol. 2007;144(6):791-811

\section{Publisher's Note}

Springer Nature remains neutral with regard to jurisdictional claims in published maps and institutional affiliations.

Ready to submit your research? Choose BMC and benefit from:

- fast, convenient online submission

- thorough peer review by experienced researchers in your field

- rapid publication on acceptance

- support for research data, including large and complex data types

- gold Open Access which fosters wider collaboration and increased citations

- maximum visibility for your research: over $100 \mathrm{M}$ website views per year

At BMC, research is always in progress.

Learn more biomedcentral.com/submissions 